\title{
Evaluation of Histomorphological Parameters to Predict Occult Nodal Metastasis in Early-Stage Oral Squamous Cell Carcinoma
}

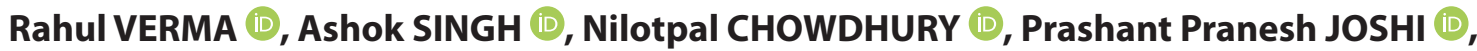 \\ Prashant DURGAPAL (D), Shalinee RAO $\mathbb{D}$, Sanjeev KISHORE (D)
}

Department of Pathology, All India Institute of Medical Sciences, RISHIKESH, INDIA

\section{ABSTRACT}

Objective: The oral squamous cell carcinoma (OSCC) treatment protocol depends upon lymph node metastasis. Elective neck dissection for early-stage OSCC ( $\mathrm{pT} 1 / \mathrm{T} 2)$ elective neck dissection reduces the morbidity rate. It also reduces the overall survival and thus it becomes important to detect lymph node metastasis in early-stage OSCC.

Material and Method: Various histomorphological parameters have been studied to predict nodal metastasis in early-stage OSCC. We aim to evaluate these parameters in the context of nodal metastasis. 78 cases of early-stage OSCC were included in the study with histopathologic parameters like tumor size, grade, tumor depth of invasion (DOI), lymphovascular invasion (LVI), perineural invasion (PNI), worst pattern of invasion (WPOI), and lymph node level.

Results: Out of the 78 patients, 32 patients had lymph node metastasis. T stage, DOI, LVI, and WPOI showed statistically significant deviance from the null model (P-values of 0.007, 0.01, 0.04 and 0.02 respectively). The Odds Ratio (OR) of T stage, DOI, LVI and WPOI were 4.45 (95\% C.I $=1.47-14.1), 4.4$ (95\% C.I =1.32-15.88), 8.12 (95\% C.I =1.002-198.20), and 3.39 (95\% C.I =1.24-9.74) respectively. On multivariate analysis (Firth logistic regression) using DOI, LVI, and WPOI as independent variables, only T-stage and WPOI retained statistical significance.

Conclusion: The prognostic information supplied by evaluating DOI, LVI, and WPOI warrants the inclusion of these parameters in the standard reporting format for all cases of OSCC.

Keywords: Oral squamous cell carcinoma, Nodal metastasis, Histomorphological parameters, Early-stage tumors

\section{INTRODUCTION}

Oral cancer is the eighth most common malignancy in the world and third most common in India with an incidence rate of 12.6 per 100000 population (1). Oral squamous cell carcinoma (OSCC) accounts for almost $90 \%$ of the oral malignancies (2). The multifactorial etiology ranges from tobacco chewing to genetics. It is also twice as common in males as compared to females with a high mortality rate and overall 5 -year survival rate of $50 \%$, which further decreases to $20-36 \%$ with nodal metastasis $(3,4)$. According to the National Comprehensive Cancer Network (NCCN) Head and Neck Cancer guidelines, the treatment modality for OSCC varies from resection of the primary with or without the neck dissection. Neck dissection is recommended in advanced stages like $\mathrm{T} 3$ and T4. However, there is disagreement over the approach for early-stage OSCC i.e. T1-2, N0. Although neck dissection in early-stage OSCC reduces the morbidity, it also exposes the patient to unnecessary neoadjuvant therapy and overtreatment. On the other hand, primary resection without neck dissection may lead to increased overall

(Turk Patoloji Derg 2022, 38:227-234)

Received: 08.04.2021 Accepted: 03.12.2021 survival compared to the elective neck dissection group (5). Thus it becomes the utmost necessity to detect lymph node metastasis, especially in early-stage OSCC. Depth of invasion (DOI) is considered to be the best predictor of occult metastatic disease. It is recommended that clinical judgment should be utilized for cases having DOI of 2-4 $\mathrm{mm}$ and elective neck dissection should be done for DOI $>4 \mathrm{~mm}$ (6). Other histological parameters like the worst pattern of invasion (WPOI), tumor differentiation, T-stage, extra-nodal extension (ENE), lymphovascular invasion (LVI), and perineural invasion (PNI) are also being studied as predictors of local and distant occult metastasis, thus collaborating in the overall decisionmaking for elective nodal dissection and further helping in reducing the incidence of treatment failure $(7,8)$. These histological parameters can be used to create a predictive model to ascertain the risk of metastasis in early-stage OSCC and further aiding in treatment decision-making. Various risk prediction models have been suggested by the authors to predict the nodal metastasis in the early as well as late-stage OSCC (9-11). Most of the scores and

Correspondence: Rahul VERMA

Department of Pathology, All India Institute of Medical Sciences, RISHIKESH, INDIA

E-mail: rahulsrhu@gmail.com Phone: +91997 1831328 
systems are being validated in the western countries only with an exception to the Brandwein Gensler risk model which was validated in the Indian scenario by Chaturvedi et al (9). A new scoring system, the Aditi-Nuzhat Lymphnode Prediction Score (ANLPS) System, was developed by Arora et al. exclusively on the Indian population for early-stage OSCC (11). Our study aims to analyze various histomorphological parameters of early-stage OSCC as predictors of occult nodal metastasis.

\section{MATERIAL and METHODS}

This retrospective analytical study was conducted in the Department of Pathology, in a tertiary care hospital in North India, by reviewing the archival data of all the OSCC patients who went for primary tumor resection with or without neck node dissection during the period of one year from January 2019 to December 2020. Patients with biopsy- proven OSCC and pathological stage pT1/T2 were included in the study. Patients with prior neoadjuvant therapy, recurrence, multiple tumors, verrucous carcinoma, and incomplete data were excluded from the study. After recording the demographic and clinical details, the cases were reviewed by two pathologists independently for the following parameters: tumor size, histopathological tumor grade (well, moderate and poorly differentiated), pathological tumor stage (TNM), DOI, regional lymph node metastasis along with the cervical level, LVI, PNI, and WPOI. On histology, the tumor was graded as described by Que et al (12). Tumors showing easily recognizable squamous epithelium, abundant keratinization, intercellular bridges, minimal pleomorphism, and basally located mitotic figures were graded as well-differentiated (Grade 1). Those tumors where squamous lineage was difficult to determine, having none or minimal keratinization and marked nuclear atypia were graded as poorly differentiated (Grade 3), and tumor cells having features in between well and poorly differentiated grades with focal keratinization and pearl formation were graded as moderately differentiated (Grade 2.) DOI was measured in millimeters ( $\mathrm{mm}$ ) using an eyepiece graticule micrometer from the basement membrane of adjacent normal to the deepest point of invasion (Figure 1). WPOI was graded as 1-4 and 5. WPOI 1-4 included tumors having pushing borders (WPOI 1), finger-like tumor borders (WPOI 2), large islands of $>15$ tumor cells/ island close to $<1 \mathrm{~mm}$ to the main tumor (WPOI 3), small islands of $<15$ tumor cells/ island close to $<1 \mathrm{~mm}$ to the main tumor and dispersed tumor satellites $>1 \mathrm{~mm}$ away from the main tumor (WPOI 5, Figure 2) (13). WPOI 1-4 tumors are non-aggressive and thus were kept in one subgroup. TNM Staging was done according to the American Joint Committee on Cancer (AJCC) classification. Figure 3 shows a mandibulectomy specimen having OSCC reported as pathological T-stage 2. The level

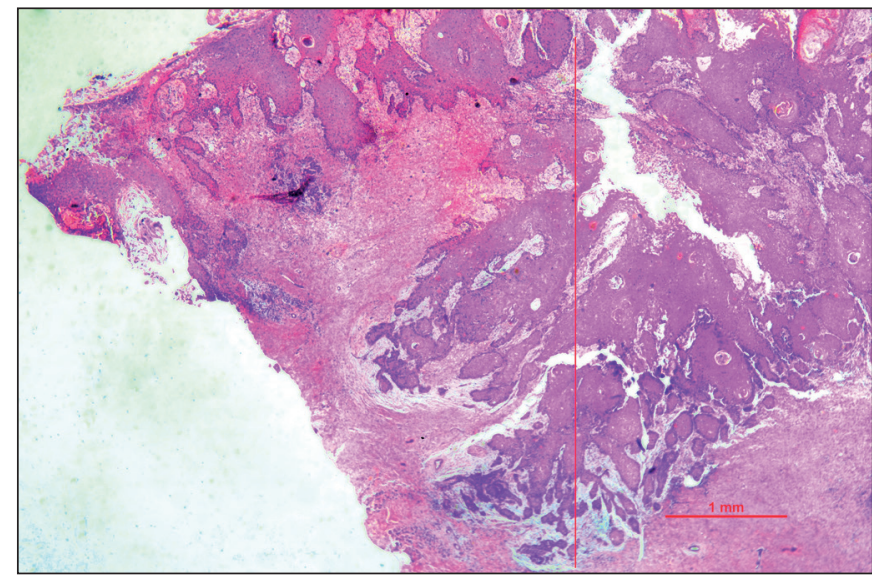

Figure 1: Depth of invasion (DOI) measurement in oral squamous cell carcinoma (OSCC). Histomorphological picture showing DOI of $3 \mathrm{~mm}$ in an OSCC pathological stage T2 (H\&E stain, 2x magnification)

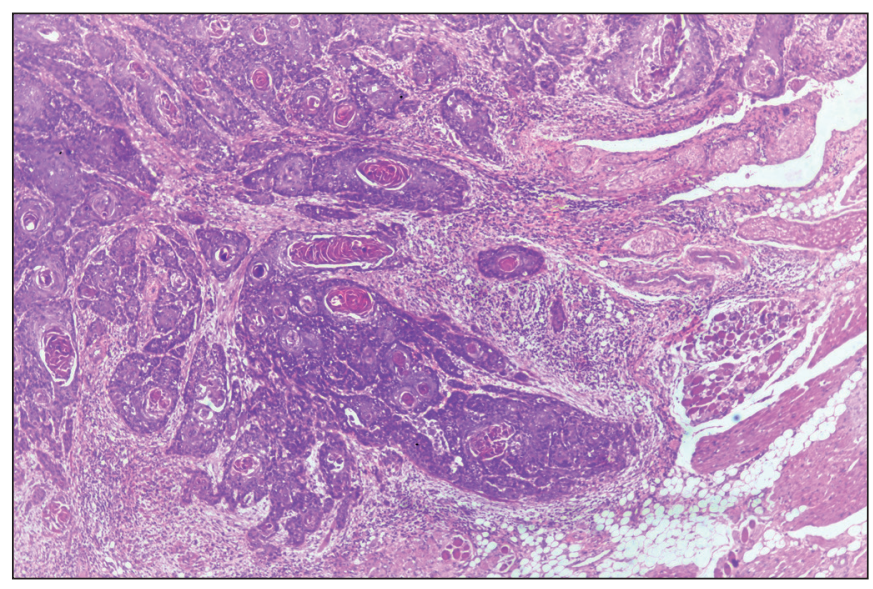

Figure 2: Histomorphological picture showing WPOI-5 an OSCC pathological stage T2 (H\&E stain, 4x magnification)

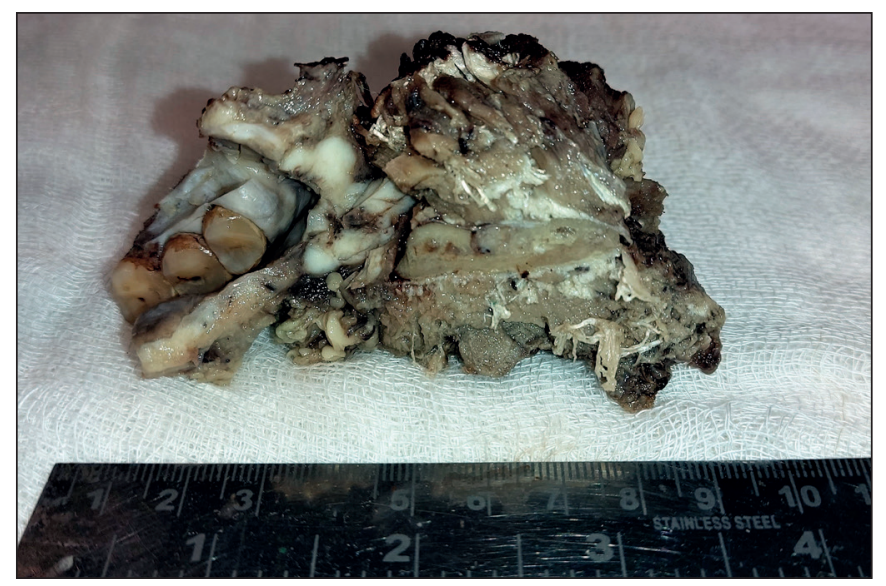

Figure 3: Gross mandibulectomy specimen showing OSCC pT2 stage. 
of lymph nodes involved was also noted for creating the prediction model of nodal metastasis.

\section{Statistical Analysis}

Statistical analyses were performed using $\mathrm{R}$ software (v 3.6.0) (14), with help from the packages "exact $2 \times 2$ " (15), "pROC" (16), and "logistf" (17). Descriptive analysis for clinical factors was done with continuous variables described as Mean \pm standard deviation and categorical variables described as proportion. For univariate analysis of the histopathological parameters with nodal status, the significance of the association between dichotomous categorical variables (LVI, WPOI, T stage: stage 1 vs. stage 2, DOI dichotomized into two groups: less than $4 \mathrm{~cm}$ and greater than or equal to $4 \mathrm{~cm}$ ) and node status was estimated by the usual Fisher's exact test and matching confidence interval (15) of the conditional odds ratio by the "exact2x2" R package. For 2x6 tables (e.g. relationship between tumor site and lymph node status), the generalized Fisher's exact test was used. The univariate analysis of DOI as a continuous variable was also done by univariate Firth logistic regression. The variables that were found statistically significant at an alpha of 0.05 were further studied in a multivariate analysis using Firth penalized logistic regression and profile penalized log-likelihood confidence intervals (18). The assumption of linearity in the logit for the Firth regression was tested by the Box-Tidwell test. We subsequently performed a ROC curve analysis for the continuous variables significantly associated with nodal metastasis on univariate analysis. Finally, Mann-WhitneyWilcoxon tests and Fisher exact tests were used to examine the relationship between the variables found significant in univariate analysis. All tests were 2 -sided with significance considered at $\mathrm{p}<0.05$.

\section{RESULTS}

The baseline demographics and clinicopathological data of a total of 189 cases were recorded (Table I). The mean age of the patients comprising 170 (89.9\%) males and 19 (10.1\%) females was $48 \pm 12.9$ years. Buccal mucosa $(n=95)$ (50.2\%) was the most common primary site in the oral mucosa followed by the tongue $(n=60)(31.7 \%)$. Most of the cases were moderately differentiated histological grade $\mathrm{n}=112(59.2 \%)$ and T4a pathological stage $\mathrm{n}=74(39.6 \%)$. A total of $90(47.6 \%)$ cases were found to be nodal positive with maximum cases $(n=25)(27.7 \%)$ falling in the N1 pathological stage. A total of 78 cases were found to be of the pT1/T2 stage. These cases were included in the study for further analysis.
Table I: Baseline demographics and clinicopathological data of all cases.

\begin{tabular}{lc}
\hline Variable & Value \\
\hline Patients (N) & 189 \\
\hline Age (Mean \pm sd) & $48 \pm 12.9$ years \\
\hline Gender & \\
Male & $170(89.9 \%)$ \\
Female & $19(10.1 \%)$ \\
\hline Tumor site & \\
Alveolar Process & $17(8.9 \%)$ \\
Buccal Mucosa & $94(50.2 \%)$ \\
Gingivo-buccal sulcus & $6(3.1 \%)$ \\
Lip & $3(1.5 \%)$ \\
Maxilla & $2(1 \%)$ \\
Palate & $4(2.1 \%)$ \\
Paranasal sinus & $1(0.5 \%)$ \\
Retromolar & $1(0.5 \%)$ \\
Tongue & $61(31.7 \%)$ \\
\hline Histological Grade & \\
Well differentiated & $75(39.6 \%)$ \\
Moderately differentiated & $112(59.2 \%)$ \\
Poorly differentiated & $2(0.01 \%)$ \\
\hline pT stage & \\
T1 & $26(13.7 \%)$ \\
T2 & $53(28 \%)$ \\
T3 & $33(11.6 \%)$ \\
T4a & $74(39.6 \%)$ \\
T4b & $1(0.5 \%)$ \\
\hline pN ${ }^{\star}$ (Total positive) & $93(49.2 \%)$ \\
N1 & $25(26.8 \%)$ \\
N2 & $3(3.3 \%)$ \\
N2a & $4(4.3 \%)$ \\
N2b & $28(30.1 \%)$ \\
N2c & $8(8.6 \%)$ \\
N3 & $2(2.1 \%)$ \\
N3b & $22(23.6 \%)$ \\
\hline Tumor size, cm [Mean $(S D)]$ & $3.7(2.6)$ \\
\hline DOI, mm (mean (SD) & $12.7(10.3)$ \\
\hline LVI (Total positive) & $23(12.1 \%)$ \\
\hline PNI (Total positive) & $32(16.9 \%)$ \\
\hline WPOI 1-4 & $94(49.7 \%)$ \\
WPOI 5 & $95(50.2 \%)$ \\
\hline & \\
\hline & \\
\hline &
\end{tabular}

${ }^{\star}$ Pathological TNM staging.

DOI: Depth of invasion, LVI: Lymphovascular invasion, PNI: Perineural invasion, WPOI: Worst pattern of invasion. 


\section{Clinical Parameters of T1/T2 Tumors}

Table II summarizes the results of the clinical and demographic parameters of early-stage OSCC (T1/T2) to evaluate them as predictors of nodal metastasis. None of the parameters was statistically significant to predict the nodal metastasis.
Histomorphological Parameters of Early-Stage OSCC (T1/T2)

Table III summarizes the association of various histomorphological parameters with the lymph node status. Out of all the parameters, four parameters composed of the T-stage, DOI, LVI, and WPOI were statistically significant.

Table II: Demographic and clinical parameters in early-stage OSCC (T1/T2).

\begin{tabular}{lccc}
\hline Parameter & LN positive $(\mathbf{n}=\mathbf{3 2})$ & LN negative $(\mathbf{n}=\mathbf{4 6})$ & p value \\
\hline Age $($ Mean \pm sd) & $47.1 \pm 12.1$ years & $46.5 \pm 13.7$ years & $0.85^{*}$ \\
\hline Gender & 27 & 44 & $0.12^{* *}$ \\
Male & 05 & 2 & $0.12^{* * *}$ \\
Female & & & \\
\hline Tumor site & 2 & 0 & \\
Alveolar Process & 12 & 22 & \\
Buccal Mucosa & 2 & 0 & \\
Gingivo-buccal sulcus & 16 & 20 & \\
Tongue & 0 & 1 & \\
Lip & 0 & 2 & \\
Maxilla & 0 & & \\
Palate & & & \\
\hline
\end{tabular}

${ }^{*}$ t-test ${ }^{* *}$ Fisher exact test ${ }^{* * *}$ Generalized Fisher exact test.

Table III: Histomorphological parameters in early-stage OSCC (T1/T2). The statistical significance has been tested by the Fisher exact test, with corresponding Confidence intervals, unless indicated otherwise.

\begin{tabular}{|c|c|c|c|c|c|}
\hline Parameter & Lymph Node positive $(n=32)$ & Lymph Node negative $(n=46)$ & OR & 95\%CI & p-value \\
\hline Histological Grade & & & 0.87 & $0.33-2.33$ & 0.82 \\
\hline Grade 1 & 15 & 20 & & & \\
\hline Grade 2 & 17 & 26 & & & \\
\hline Grade 3 & 0 & 0 & & & \\
\hline pT stage & & & 4.45 & $1.47-14.1$ & 0.007 \\
\hline T1 & 05 & 21 & & & \\
\hline $\mathrm{T} 2$ & 27 & 25 & & & \\
\hline DOI, mm & & & 4.4 & $1.32-15.88$ & 0.01 \\
\hline$\leq 3.99$ & 04 & 18 & & & \\
\hline$\geq 4.00$ & 28 & 28 & & & \\
\hline DOI (As continuous & riable) & & 1.14 & $1.01-1.31$ & $0.04^{*}$ \\
\hline LVI & & & 8.12 & $1.002-198.20$ & 0.04 \\
\hline Present & 05 & 01 & & & \\
\hline Absent & 27 & 45 & & & \\
\hline PNI & & & 2.03 & $0.41-11.03$ & 0.43 \\
\hline Present & 04 & 03 & & & \\
\hline Absent & 28 & 43 & & & \\
\hline $\begin{array}{l}\text { Worst pattern of } \\
\text { invasion }\end{array}$ & & & 3.39 & $1.24-9.74$ & 0.02 \\
\hline WPOI 1-4 & 12 & 30 & & & \\
\hline WPOI 5 & 20 & 16 & & & \\
\hline
\end{tabular}

${ }^{*}$ Firth Logistic regression. DOI: Depth of invasion, LVI: Lymphovascular invasion, PNI: Perineural invasion, WPOI: Worst pattern of invasion 
Table IV: Result of multivariate Firth logistic regression done using the variables found to be statistically significant on univariate analysis, with the $95 \% \mathrm{CI}$ of the odds ratio.

\begin{tabular}{lccccc}
\hline & Coefficient & Odds Ratio (OR) & Lower 95\% C.I. of OR & Upper 95\% C.I. of OR & p-value \\
\hline Intercept & -3.21 & 0.04 & 0.004 & 0.27 & 0.0006 \\
\hline DOI ( mm) & 0.02 & 1.024 & 0.88 & 1.19 & 0.75 \\
\hline LVI & 1.54 & 4.66 & 0.67 & 58.88 & 0.12 \\
\hline T stage (2 vs 1) & 1.29 & 3.64 & 1.09 & 13.54 & 0.035 \\
\hline WPOI ( 5 vs 4) & 1.009 & 2.74 & 1.026 & 7.62 & 0.044 \\
\hline
\end{tabular}

Likelihood ratio test $=16.18$ on $4 \mathrm{df}, \mathrm{p}=0.002$

DOI: Depth of invasion, LVI: Lymphovascular invasion, WPOI: Worst pattern of invasion

Table V: The Specificity and Sensitivity at various thresholds for the ROC curve analysis of the Depth of Invasion (DOI), along with the Area under curve (AUC) with 95\% Confidence intervals by the deLong Method.

\begin{tabular}{lccccc}
\hline Threshold & $\geq 3 \mathrm{~mm}$ & $\geq 4 \mathrm{~mm}$ & $\geq 5 \mathrm{~mm}$ & $\geq 6 \mathrm{~mm}^{\star}$ & $\geq 7 \mathrm{~mm}$ \\
\hline Specificity & 0.28 & 0.39 & 0.5 & 0.61 & 0.65 \\
\hline Sensitivity & 0.94 & 0.87 & 0.72 & 0.69 & 0.59 \\
\hline AUC & $0.67(95 \%$ CI: $0.55-0.79)$ & & & & \\
\hline
\end{tabular}

* Best Threshold by Youden's J

Other parameters did not show a statistically significant correlation with nodal metastasis in early-stage OSCC (T1/T2). On multivariate analysis, only WPOI and T-stage retained their significance (Table IV), but these results are limited by a small sample size. The Box-Tidwell test did not reveal a statistically significant violation of the assumption of linearity of the logit when using the Firth penalized logistic regression.

On a ROC curve analysis for DOI, a cut off of $6 \mathrm{~mm}$ was found to give the highest sum of sensitivity and specificity, and thus the Youden J. The results of the sensitivity and specificity at the region of highest performance along with the area under the curve are given in Table V.

We also performed tests for the association between the significant factors found in univariate analysis. Among these factors, DOI was significantly associated with the T-stage (P-value $<0.001$ by the Mann-Whitney-Wilcoxon test) and showed a trend towards significance with LVI ( $\mathrm{p}$-value of 0.09 by the Mann-Whitney-Wilcoxon test test). None of the other factors showed a significant association with each other.

\section{DISCUSSION}

The oral cancer burden worldwide is approximately $300000 /$ year out of which India has the highest share (20\%). OSCC is the commonest malignancy in the oral cavity with a male to female ratio of 3:1 (19). According to NCCN guidelines, the treatment protocol for OSCC depends upon the TNM staging. The mainstay of the treatment is primary resection with or without neck node dissection. For advanced-stage OSCC, i.e. T3-T4, treatment includes primary resection with neck node dissection followed by neoadjuvant therapy if necessary. However, for early-stage OSCC, i.e. T1-T2, there is an option for either performing elective neck dissection or observing with follow up so that loco-regional recurrence is detected early and salvage surgery can be performed (20). Although OSCC with no clinical nodal involvement rarely $(<10 \%)$ presents with nodal metastasis, it is imperative to detect occult metastasis in early-stage OSCC. Elective neck dissection provides comprehensive clearance of nodes, increases overall survival rate, and prevents loco-regional recurrences, in addition to increasing the aesthetic and functional morbidity (21). Several authors have compared elective node dissection and follow up observation in early-stage OSCC and found the nodal recurrence rate to be higher in the observation group compared to the elective node dissection group. These patients were further subjected to salvage surgery, which involves aggressive approach and increases mortality (22-24). Determining which approach to follow thus requires multiple large-scale studies and comprehensive reviews.

The various histological parameters are being studied as prognostic factors associated with the survival rate in OSCC (25). We studied the histological parameters like pathological TNM stage, tumor grade, DOI, WPOI, PNI, and LVI. 
DOI has been considered as an important prognostic as well as regional nodal involvement parameter in many studies (11,26-28). The National Comprehensive Cancer Network (NCCN) Head and Neck Cancer guidelines suggest elective neck dissection in tumors with DOI greater than $4 \mathrm{~mm}$. DOI is different from the tumor thickness as the former one is measured from the basement membrane between tumor and adjacent normal surface to the maximum depth of the tumor whereas tumor thickness also takes into account the mucosal surface of the tumor. The AJCC 8th edition now uses DOI for staging (29). In our study, DOI failed to retain its significance in the multivariate analysis, possibly due to its association with the T-stage (p-value $<0.001$ using the Mann-Whitney-Wilcoxon test) causing multi collinearity and due to the small sample size. However, due to the importance of DOI found in other papers, we still conducted a univariate ROC curve analysis of DOI (Table $\mathrm{V})$, and reported the area under the curve and estimated best cut-off according to our analysis. DOI was found to have a modest predictive value in such a univariate analysis.

The worst pattern of invasion (WPOI) is an important prognostic factor for oral cavity squamous carcinomas (30-32). Five different patterns of WPOI (1-5) have been described (13). Various studies suggested that WPOI 5 is associated with a higher risk of lymph node metastasis compared to the other patterns (WPOI 1-4) in early-stage OSCC $(11,33,34)$. Our findings were also in concordance with these studies. Moreover when measured together with DOI, the chances of predicting the occult metastasis increase. However, some studies have shown discordant results suggesting no effect of WPOI on occult metastasis $(26,35)$.

Lymphovascular invasion (LVI) was also associated with lymph nodal metastasis, with a high odds ratio. However, the predictive effect of LVI was limited by the relatively low number of cases having a positive LVI. The positive cases, however, were associated with a greatly increased risk of metastasis (5 out of 6 cases in our study having LVI had lymph nodal metastasis). Even in the multivariate analysis, even though LVI by itself did not have a significant $\mathrm{p}$-value at an alpha of 0.05 .

The T-stage was another important prognostic factor that also retained its importance in multivariate analysis. In doing so, it possibly competed against DOI due to significant association and caused the latter to lose its significance. This effect was exacerbated by the small sample size. However, we believe that all the factors that were significant in the univariate analysis are important predictors for nodal metastasis in early-stage OSCC, and information from all the factors should be considered.
It is pertinent to mention that while reporting histopathological samples from OSCC these parameters should be evaluated in the standard reporting format as they are associated with a high risk of nodal metastasis. In our study, grade and perineural invasion were not statistically significant to provide any information regarding metastasis.

Multifactorial predictive models and scoring systems have been suggested by authors. These models evaluate multiple histomorphological parameters at different levels to predict metastasis. Multiple variables seem to predict more accurately when evaluated in large-scale studies than individual ones $(11,28,36)$. We found WPOI 5 and T-stage as better predictors in early-stage OSCC, while it was extremely likely that DOI and LVI have a significant association with the same. However, the study was limited due to the small sample size. This led to sparsity of data, which carries a risk of optimistic estimates of odds ratios by ordinary logistic regression. Therefore, we carried out a Firth logistic regression, which is a standard method for reducing small sample bias. The Firth method uses a method known as penalized likelihood (18). A possible alternative would have been to use exact logistic regression, e.g. using the R package "elrm". However, exact logistic regression is a computationally intensive Monte Carlo Markov chain (MCMC) method. The presence of a continuous variable as a predictor further increases the sparsity, demanding greater computational power. In our case, we did not get valid exact logistic regression results for our multivariate analysis even after 10 million iterations leaving us the choice of using just penalization methods like the Firth logistic regression.

We evaluated some of the histological parameters involved in predicting the nodal metastasis in early-stage OSCC. T-stage, WPOI, DOI, and LVI were the major significant parameters that influenced the nodal metastasis on univariate analysis. Inclusion of these parameters in routine standard reporting will increase the likelihood of predicting the nodal metastasis and hence guiding the clinicians to choose the best treatment protocol for the patients.

\section{Conflict of Interest}

None.

\section{Authorship Contributions}

Concept: RV, Design: AS, Data collection or processing: RV, Analysis or Interpretation: NC, Literature search: PPJ, Writing: PD, Approval: SR, SK. 


\section{REFERENCES}

1. Petersen PE. Strengthening the prevention of oral cancer: The WHO perspective. Community Dent Oral Epidemiol. 2005;33:397-9.

2. Ferlay J, Autier P, Boniol M, Heanue M, Colombet M, Boyle P. Estimates of the cancer incidence and mortality in Europe in 2006. Ann Oncol. 2007;18:581-92.

3. Jin X, Liu D, Zhao X, Zhou Y, Jiang L, Li J, Zeng X, Chen Q. Analysis of clinicopathological characteristics associated with the outcome of oral squamous cell carcinoma and the establishment of tissue microarrays. Oncol Lett. 2016;12:3175-82.

4. Goerkem M, Braun J, Stoeckli SJ. Evaluation of clinical and histomorphological parameters as potential predictors of occult metastases in sentinel lymph nodes of early squamous cell carcinoma of the oral cavity. Ann Surg Oncol. 2010;17:527-35.

5. Nieuwenhuis EJ, Castelijns JA, Pijpers R, van den Brekel MW, Brakenhoff RH, van der Waal I, Snow GB, Leemans CR. Wait-and-see policy for the N0 neck in early-stage oral and oropharyngeal squamous cell carcinoma using ultrasonographyguided cytology: Is there a role for identification of the sentinel node? Head Neck. 2002;24:282-9.

6. National comprehensive cancer network. Head and neck (Version 1.2016) (Accessed on February 4, 2020). Available from:https:// oralcancerfoundation.org/wp-content/uploads/2016/09/headand-neck.pdf.

7. Adel M, Kao HK, Hsu CL, Huang JJ, Lee LY, Huang Y, Browne T, Tsang NM, Chang YL, Chang KP. Evaluation of lymphatic and vascular invasion in relation to clinicopathological factors and treatment outcome in oral cavity squamous cell carcinoma. Medicine (Baltimore). 2015;94:e1510.

8. Keski-Säntti H, Atula T, Tikka J, Hollmén J, Mäkitie AA, Leivo I. Predictive value of histopathologic parameters in early squamous cell carcinoma of oral tongue. Oral Oncol. 2007;43:1007-13.

9. Chaturvedi A, Husain N, Misra S, Kumar V, Gupta S, Akhtar N, Lakshmanan M, Garg S, Arora A, Jain K. Validation of the brandwein gensler risk model in patients of oral cavity squamous cell carcinoma in North India. Head Neck Pathol. 2020;14:61622.

10. Anneroth G, Batsakis J, Luna M. Review of the literature and a recommended system of malignancy grading in oral squamous cell carcinomas. Scand J Dent Res. 1987;95:229-49.

11. Arora A, Husain N, Bansal A, Neyaz A, Jaiswal R, Jain K, Chaturvedi A, Anand N, Malhotra K, Shukla S. Development of a new outcome prediction model in early-stage squamous cell carcinoma of the oral cavity based on histopathologic parameters with multivariate analysis: The Aditi-Nuzhat Lymphnode Prediction Score (ANLPS) System. Am J Surg Pathol. 2017;41:950-60.

12. Que SKT, Zwald FO, Schmults CD. Cutaneous squamous cell carcinoma: Incidence, risk factors, diagnosis, and staging. J Am Acad Dermatol. 2018;78:237-47.

13. El-Naggar AK, Chan JKC, Takata T, Grandis JR, Slootweg PJ. The fourth edition of the head and neck World Health Organization blue book: Editors' perspectives. Hum Pathol. 2017;66:10-12.
14. Team RC. A language and environment for statistical computing. Vienna, Austria: R Foundation for Statistical Computing. (Accessed on Dec 27 2021). Available from: http://www. R-project. org.

15. Fay MP. Confidence intervals that match Fisher's exact or Blaker's exact tests. Biostatistics. 2010;11:373-4.

16. Robin X, Turck N, Hainard A, Tiberti N, Lisacek F, Sanchez JC, Müller M.pROC: An open-source package for R and S+ to analyze and compare ROC curves. BMC Bioinformatics. 2011;12:77.

17. Firth's Bias-Reduced Logistic Regression [R package logistf version 1.24]. (Accessed on December 28 2021). Available from: https://cran.r-project.org/web/packages/logistf/index.html.

18. Heinze G, Puhr R. Bias-reduced and separation-proof conditional logistic regression with small or sparse data sets. Stat Med. 2010;29:770-7.

19. Singh MP, Kumar V, Agarwal A, Kumar R, Bhatt ML, Misra S. Clinico-epidemiological study of oral squamous cell carcinoma: A tertiary care centre study in North India. J Oral Biol Craniofac Res. 2016;6:31-4.

20. Colevas AD, Yom SS, Pfister DG, Spencer S, Adelstein D, Adkins D, Brizel DM, Burtness B, Busse PM, Caudell JJ, Cmelak AJ, Eisele DW, Fenton M, Foote RL, Gilbert J, Gillison ML, Haddad RI, Hicks WL, Hitchcock YJ, Jimeno A, Leizman D, Maghami E, Mell LK, Mittal BB, Pinto HA, Ridge JA, Rocco J, Rodriguez CP, Shah JP, Weber RS, Witek M, Worden F, Zhen W, Burns JL, Darlow SD. NCCN Guidelines insights: Head and neck cancers, version 1.2018. J Natl Compr Canc Netw. 2018;16:479-490.

21. Shah JP, Candela FC, Poddar AK. The patterns of cervical lymph node metastases from squamous carcinoma of the oral cavity. Cancer. 1990;66:109-13.

22. Kligerman J, Lima RA, Soares JR, Prado L, Dias FL, Freitas EQ, Olivatto LO. Supraomohyoid neck dissection in the treatment of T1/T2 squamous cell carcinoma of oral cavity. Am J Surg. 1994;168:391-4.

23. Yuen AP, Ho CM, Chow TL, Tang LC, Cheung WY, Ng RW, Wei WI, Kong CK, Book KS, Yuen WC, Lam AK, Yuen NW, Trendell-Smith NJ, Chan YW, Wong BY, Li GK, Ho AC, Ho WK, Wong SY, Yao TJ. Prospective randomized study of selective neck dissection versus observation for N0 neck of early tongue carcinoma. Head Neck. 2009;31:765-72.

24. D’Cruz AK, Vaish R, Kapre N, Dandekar M, Gupta S, Hawaldar R, Agarwal JP, Pantvaidya G, Chaukar D, Deshmukh A, Kane S, Arya S, Ghosh-Laskar S, Chaturvedi P, Pai P, Nair S, Nair D, Badwe R; Head and Neck Disease Management Group. Elective versus therapeutic neck dissection in node-negative oral cancer. N Engl J Med. 2015;373:521-9.

25. Taghavi N, Yazdi I. Prognostic factors of survival rate in oral squamous cell carcinoma: Clinical, histologic, genetic and molecular concepts. Arch Iran Med. 2015;18:314-9.

26. Kane SV, Gupta M, Kakade AC, D’ Cruz A. Depth of invasion is the most significant histological predictor of subclinical cervical lymph node metastasis in early squamous carcinomas of the oral cavity. Eur J Surg Oncol. 2006;32:795-803. 
27. Melchers LJ, Schuuring E, van Dijk BA, de Bock GH, Witjes MJ, van der Laan BF, van der Wal JE, Roodenburg JL. Tumour infiltration depth $\geq 4 \mathrm{~mm}$ is an indication for an elective neck dissection in pT1cN0 oral squamous cell carcinoma. Oral Oncol. 2012;48:337-42.

28. Brockhoff HC 2nd, Kim RY, Braun TM, Skouteris C, Helman JI, Ward BB. Correlating the depth of invasion at specific anatomic locations with the risk for regional metastatic disease to lymph nodes in the neck for oral squamous cell carcinoma. Head Neck. 2017;39:974-9.

29. Lydiatt WM, Patel SG, O'Sullivan B, Brandwein MS, Ridge JA, Migliacci JC, Loomis AM, Shah JP. Head and neck cancers-major changes in the American Joint Committee on cancer eighth edition cancer staging manual. CA Cancer J Clin. 2017;67:12237.

30. Brandwein-Gensler M, Smith RV, Wang B, Penner C, Theilken A, Broughel D, Schiff B, Owen RP, Smith J, Sarta C, Hebert T, Nason R, Ramer M, DeLacure M, Hirsch D, Myssiorek D, Heller K, Prystowsky M, Schlecht NF, Negassa A. Validation of the histologic risk model in a new cohort of patients with head and neck squamous cell carcinoma. Am J Surg Pathol. 2010;34:67688 .

31. Brandwein-Gensler M, Teixeira MS, Lewis CM, Lee B, Rolnitzky L, Hille JJ, Genden E, Urken ML, Wang BY. Oral squamous cell carcinoma: Histologic risk assessment, but not margin status, is strongly predictive of local disease-free and overall survival. Am J Surg Pathol. 2005;29:167-78.
32. Li Y, Bai S, Carroll W, Dayan D, Dort JC, Heller K, Jour G, Lau H, Penner C, Prystowsky M, Rosenthal E, Schlecht NF, Smith RV, Urken M, Vered M, Wang B, Wenig B, Negassa A, BrandweinGensler M. Validation of the risk model: High-risk classification and tumor pattern of invasion predict outcome for patients with low-stage oral cavity squamous cell carcinoma. Head Neck Pathol. 2013;7:211-23.

33. Chatterjee D, Bansal V, Malik V, Bhagat R, Punia RS, Handa U, Gupta A, Dass A. Tumor budding and worse pattern of invasion can predict nodal metastasis in oral cancers and associated with poor survival in early-stage tumors. Ear Nose Throat J. 2019;98:E112-E119.

34. Hiratsuka H, Miyakawa A, Nakamori K, Kido Y, Sunakawa H, Kohama G. Multivariate analysis of occult lymph node metastasis as a prognostic indicator for patients with squamous cell carcinoma of the oral cavity. Cancer. 1997;80:351-6.

35. Chang YC, Nieh S, Chen SF, Jao SW, Lin YL, Fu E. Invasive pattern grading score designed as an independent prognostic indicator in oral squamous cell carcinoma. Histopathology. 2010;57:295-303.

36. Siriwardena BSMS, Rambukewela IK, Pitakotuwage TN, Udagama MNGPK, Kumarasiri PVR, Tilakaratne WM. A predictive model to determine the pattern of nodal metastasis in Oral Squamous Cell Carcinoma. Biomed Res Int. 2018;2018:8925818. 